\title{
Sistem Pengendalian Manajemen dan Proactive Working Behavior
}

\author{
Nindhika Rina Ayuning Aji \\ Universitas Katolik Soegijapranata \\ nindhikarina@gmail.com
}

\begin{abstract}
This study examines the moderating effect of flexible role orientation on the relationship between lack of controllability dan proactive work behaviour. Flexible role orientation encourages proactive cognitive motivational states. When employees feel flexible in role orientation, they feel more responsibility for organizational goals. On the other hand, managers who feel inferior in their level of responsibility will form a narrow role with a rigid role orientation. Flexible roles describe cognitive conditions that arise from the need to achieve a higher level of organizational responsibility. This study replicates Burkert et a.l's research additional external variabels. This research uses managers of manufacturing companies in the city of Semarang. The data analysis employs linear regression technique and Sobel Test. Results show that flexible role orientation can mediate the relationship between lack of controllability and proactive work behavior
\end{abstract}

Keywords: flexible role orientation, lack of controllability, proactive work behaviour

\begin{abstract}
Abstrak
Penelitian ini bertujuan untuk menganalisis pengaruh keberadaan sistem pengendalian manajemen terhadap proactive work behaviour. Orientasi peran yang fleksibel mendorong motivasi kognitif proaktif dan kontras dengan keadaan pasif. Ketika karyawan merasakan orientasi peran yang fleksibel, mereka merasakan lebih banyak tanggung jawab untuk tujuan organisasi. Penelitian ini mereplikasi riset Burkert et al. (2016) dengan menambah variabel eksternal. Sampel yang digunakan adalah manager yang bekerja pada perusahaan-perusahan manufaktur di kota Semarang. Teknik analisis data adalah regresi linear dan Sobel Test. Hasil penelitian menunjukkan flexible role orientation dapat memediasi hubungan antara lack of controllability dan proactive work behaviour
\end{abstract}

Kata kunci: flexible role orientation, lack of controllability, proactive work behaviour

\section{PENDAHULUAN}

Sistem pengendalian manajemen adalah konsep sistem pengendalian manajemen yang berkaitan dengan proses pengendalian, dan struktur pengendalian. Struktur diartikan sebagai suatu kerangka sistem yang terdiri dari bagian-bagian yang membentuk sistem itu sendiri, sedangkan proses didalam konsep sistem pengendalian manajemen adalah untuk menjelaskan bagaimana bekerjanya masing-masing bagian didalam sistem tersebut dalam pencapaian tujuannya, dan untuk memastikan bahwa hasil-hasil yang dicapai telah sesuai dengan rencana (Suadi,1999). Secara umum, sistem pengendalian manajemen mengacu pada desain, instalasi 
dan operasi dari perencanaan manajemen dan sistem kontrol. Seperti sistem kontrol yang merupakan struktur atau organisasi struktur atau hubungan antar unit dalam organisasi, hubungan antara pusat-pusat tanggung jawab, pengukuran kinerja dan informasi yang mengalir di antara pusat-pusat tanggung jawab tersebut. Pengendalian sangat penting untuk mendeteksi dan mencegah kesalahan agar tidak berulang serta memastikan bahwa tujuantujuan perusahaan dan rencana yang telah dirancang dapat tercapai sesuai dengan tujuan yang telah ditetapkan dalam suatu perusahaan.

Agar terciptanya kesinambungan antara satu bagian dengan bagian lainnya sehingga semua fungsi manajemen yang lain tidak akan efektif tanpa disertai fungsi pengawasan. Louis dan David (1984) memberikan rumusan tentang pengawasan sebagai proses yang menentukan apakah operasi yang sesungguhnya konsisten dengan yang direncanakan. Sementara, Handoko (1995) mengemukakan definisi pengawasan manajemen sebagai usaha sistematik untuk menetapkan standar pelaksanaan dengan tujuan-tujuan perencanaan, merancang sistem informasi umpan balik, membandingkan kegiatan yang telah dilakukan sebelumnya dengan standar yang telah ditetapkan sebelumnya, menentukan dan mengukur penyimpangan-penyimpangan, serta mengambil tindakan koreksi yang diperlukan untuk menjamin bahwa semua sumber daya perusahaan dipergunakan dengan efektif dan efisien dalam mencapaian suatu tujuan perusahaan. Dengan demikian, pengawasan merupakan suatu kegiatan yang berusaha untuk mengendalikan sesuatu agar dapat terlaksana serta dapat berjalan sesuai dengan bagaimana mestinya. Sedangkan pada kenyataannya sering kali terjadi kurangnya pengawasan (lack of direction).

Kurangnya pengawasan terjadi ketika kinerja pegawai kurang memuaskan yang dipicu kurangnya pemahaman tentang apa yang diinginkan organisasi. Hal ini menimbulkan perilaku disfungsional dalam diri karyawan. Oleh karena itu, sistem pengendalian manajemen yang efektif sangat diperlukan untuk mencapai tujuan organisasi (Merchant and Stede, 2012). Sering kali karyawan tidak mengerti apa yang diharapkan perusahaan dari mereka. Akibatnya, beberapa dari mereka tidak bekerja sesuai dengan harapan organisasi karena tidak ada motivasi. Permasalahan motivasi sering terjadi karena tujuan individu dan organisasi tidak sejalan, dimana pegawai hanya berpikir untuk diri mereka sendiri. (Merchant and Stede, 2012). Pengendalian yang lemah menyulitkan perusahaan untuk mengukur kinerja yang akhirnya dapat menurunkan motivasi dan menyebabkan tingkat role stress yang lebih tinggi (Giraud et al., 2008). Secara khusus, Simons (2010) menyatakan bahwa lemahnya pengendalian menghalangi manajer untuk dapat berkomunikasi dan bekerjasama dengan manajer lain dalam rangka mencari solusi atas masalah-masalah yang ada pada tingkat organisasi yang lebih tinggi (Crant, 2000).

Burkert et al. ,2016) meneliti dampak kurangnya pengendalian terhadap perilaku proaktif karyawan. Hasil penelitian menunjukkan bahwa karyawan memiliki tingkat perilaku kerja proaktif yang lebih tinggi ketika perusahaan mengandalkan proses pelaksanaan yang kurang terkontrol. Kurangnya pengendalian meningkatkan konflik peran yang pada akhirnya mendorong orientasi peran yang lebih fleksibel serta menghasilkan tingkat perilaku proaktif yang lebih tinggi.

Penelitian ini bertujuan untuk menguji ulang penelitian Burkert et al., (2016) dengan menambah variabel eksternal. Sampel yang akan digunakan adalah para manajer yang bekerja pada perusahaan manufaktur di kota Semarang. Penelitian ini penting untuk mengetahui apakah manajer memiliki perilaku yang sama ketika berada dalam situasi lack of controllability. Sementara, orientasi peran yang fleksibel mendorong munculnya motivasi kognitif proaktif (Parker et al. 2006) yang kontras dengan keadaan pasif. Ketika karyawan merasakan orientasi peran yang fleksibel, mereka merasakan lebih banyak tanggung jawab untuk tujuan organisasi (Parker 2007). 


\section{TINJAUAN LITERATUR DAN PERUMUSAN HIPOTESIS}

\section{Sistem Pengendalian Manajemen}

Pengendalian manajemen merupakan suatu proses untuk memotivasi dan memberi semangat serta dorongan kepada anggota organisasi untuk dapat melaksanakan kegiatan kegiatan dalam rangka mencapai tujuan organisasi. Pengendalian manajemen juga merupakan suatu proses untuk mendeteksi dan mengoreksi kesalahan yang tidak disengaja maupun ketidakbenaran yang disengaja. Pengendalian manajemen dalam suatu perusahaan mencakup aspek-aspek perencanaan, pengorganisasian serta pengarahan fungsi-fungsi manajemen dengan adanya koordinasi pada beberapa bagian yang ada di dalam perusahaan. Setiap periodenya akan dilaksanakan kegiatan evaluasi serta strategi apa saja yang akan dilakukan oleh perusahaan, dengan itu pengendalian dapat dilakukan untuk menjamin bahwa semua strategi akan berjalan sesuai dengan keinginan perusahaan.

Pengendalian manajemen yang efektif pada dasarnya memerlukan suatu prosedur yang tepat, sehingga dapat memungkinkan manajer atau perusahaan untuk melakukan pengawasan serta evaluasi terhadap input dan output dengan maksimal. Oleh karena itu, manajemen memerlukan sistem untuk menangani proses yang akan digunakan untuk menjamin organisasi dalam melaksanakan kebijakan yang ada secara efektif dan efisien. Menurut Suadi (1996), pengendalian manajemen adalah sistem yang terdiri dari beberapa anak sistem yang saling berkaitan, yaitu pemrograman, penganggaran akuntansi, pelaporan dan pertanggung jawaban untuk membantu manajemen mempengaruhi orang lain dalam sebuah perusahaan agar mau mencapai tujuan perusahaan melalui strategi tertentu secara efektif dan efisien.

\section{Teori Peran}

Menurut teori peran (role theory), individu sebagai pelaku sosial mempelajari perilaku yang sesuai dengan posisi mereka di masyarakat (Kahn, et al., 1964). Peran (role) adalah konsep sentral dari teori peran. Kajian mengenai teori peran tidak lepas dari definisi peran dan berbagai istilah perilaku didalamnya. Peran mencerminkan posisi seseorang dalam sistem sosial dengan hak dan kewajiban, kekuasaan dan tanggung jawab yang menyertainya. Untuk dapat berinteraksi satu sama lain, orang-orang memerlukan cara tertentu guna mengantisipasi perilaku orang lain. Setiap orang memiliki peran masing-masing, baik dalam pekerjaan maupun di luar itu. Masing-masing peran menghendaki perilaku yang berbeda. Dalam lingkungan pekerjaan itu sendiri seorang karyawan mungkin memiliki lebih dari satu peran, seorang karyawan bisa berperan sebagai bawahan, penyedia, anggota serikat pekerja, dan wakil dalam panitia keselamatan kerja.

Teori peran merupakan salah satu teori sentral dalam psikologi sosial dan secara luas digunakan dalam kajian akademis. Kahn et al. (1964) membahas tentang peran sebagai atasan yang mentransmisikan ekspektasi peran ke bawahan. Orang yang fokus pada deskripsi pekerjaan mereka akan merasakan kejelasan peran dan tahu apa yang diharapkan dari mereka. Persepsi individu tentang peran mereka memiliki efek fungsional ataupun disfungsional seperti kepuasan dan komitmen kerja. Persepsi peran adalah keadaan kognitif yang menggambarkan bagaimana individu mengalami peran mereka sendiri. Respon perilaku yang dihasilkan dari persepsi peran tersebut dapat bersifat pasif, seperti ketidakaktifan karena stres peran atau komitmen kerja yang lebih tinggi yang dihasilkan dari kejelasan peran. Namun, persepsi peran juga dapat memiliki sifat aktif dan dinamis yang memungkinkan orang-orang fokus untuk secara proaktif membentuk peran atau sering disebut dengan pembuatan peran (Perrone et al., 2003, Hibah and Hofmann 2011, dan Strauss et al., 2012). 


\section{Teori Dua faktor}

Herzberg et al., (1959) menyatakan bahwa ada faktor-faktor tertentu di tempat kerja yang menyebabkan kepuasan kerja. Di lain sisi, ada pula faktor yang menyebabkan ketidakpuasan. Singkatnya, kepuasan dan ketidakpuasan kerja berhubungan satu sama lain. Faktor-faktor tersebut disebut dengan hygiene factors (faktor kesehatan) dan motivation factors (faktor pemuas). Dua faktor ini oleh Herzberg disebut faktor intrinsik dan faktor ekstrinsik. Faktor intrinsik adalah faktor yang mendorong karyawan termotivasi, yaitu daya dorong yang timbul dari dalam diri masing-masing orang. Sedangkan faktor ekstrinsik yaitu daya dorongan yang datang dari luar diri seseorang, terutama dari organisasi tempatnya bekerja.

\section{Flexible Role Orientation, Lack of Controllability dan Proactive Work Behaviour}

Simons (2010) menyatakan bahwa organisasi dapat memilih untuk tidak menerapkan kontrol perilaku yang ketat agar dapat membangkitkan perilaku tertentu, seperti komunikasi dan kolaborasi. Mengingat lingkungan yang semakin dinamis, perilaku seperti itu sangat dibutuhkan oleh organisasi. Literatur manajemen menggunakan istilah perilaku kerja yang proaktif untuk merujuk pada perilaku tersebut. Simons (2010) memberi bukti bahwa MCS dapat meningkatkan perilaku kerja proaktif. Secara khusus, Burkert et al., (2016) menunjukkan bahwa kurangnya kemampuan mengendalikan (lack of controllability) disikapi manajer dengan komunikasi dan kerja saham yang lebih intensif dengan manajer lain. Jadi, lack of controllability berhubungan dengan perilaku yang lebih proaktif dalam menjalankan pekerjaan. Namun, hubungan ini hanya bisa terjadi jika manajer memiliki orientasi peran yang lebih fleksibel.

Memasukkan flexible role orientation sebagai variabel yang memediasi hubungan dasar antara Lack of controllability dan Proactive work behaviour membutuhkan pemisahan efek dasar dari variabel utama. Dengan kata lain, penggunaan ukuran kinerja yang kurang terkendali menginduksi orientasi peran yang lebih fleksibel serta dapat mengurangi risiko mentalitas 'bukan tanggung jawab saya' (Parker,2007). Ini penting, karena mentalitas seperti itu di luar peran yang telah ditentukan pada akhirnya dapat menghasilkan 'perpindahan tujuan' (Manzoni,2002). Dengan demikian, perusahaan dapat memilih prinsip pengendalian untuk memicu orientasi peran yang lebih fleksibel. Frow et al. (2005) memprediksi lack of controllability berpengaruh tidak langsung terhadap proactive work behaviour melalui stres peran.

Literatur yang ada memprediksi dan menemukan bahwa orientasi peran yang lebih fleksibel mengarah pada kinerja pekerjaan yang lebih baik (Wu and Parker, 2011). Jika manajer menunjukkan orientasi peran yang sempit ditempat kerja, mereka akan cenderung membatasi diri pada deskripsi pekerjaan formal saja. Sedangkan manajer yang memiliki orientasi peran yang luas (melampaui persyaratan operasional), lebih bersedia untuk melakukan tugas diluar pekerjaan formal mereka. Selain itu, orientasi peran yang lebih fleksibel cenderung menghasilkan peran yang lebih kuat. Burkert et al., (2016) menyatakan peran yang lebih fleksibel meningkatkan motivasi untuk menunjukkan perilaku kerja yang proaktif.

Secara khusus, orientasi peran yang fleksibel merupakan karakter kepribadian yang stabil yang tidak dapat dipengaruhi oleh parameter desain MCS. Efek dasar dari kurangnya kemampuan kontrol menjadi lebih tinggi pada orientasi peran fleksibel yang tinggi dan lebih rendah pada orientasi peran yang kurang fleksibel. Dengan demikian, manajer dengan tingkat orientasi peran yang fleksibel memiliki kemampuan dalam memotivasi sehingga mereka menunjukkan perilaku yang lebih proaktif dalam bekerja. Namun perlu dicatat, rendahnya kemampuan dalam mengendalikan tidak selalu menghasilkan perilaku kerja yang lebih proaktif. Lack of controlability akan mendorong orientasi kerja yang lebih fleksibel dan 
akhirnya memicu munculnya kerja yang proaktif. Hipotesis pengaruh peran yang fleksibel terhadap hubungan antara lack of controlability dan proactive work behaviour dapat dinyatakan sebagai berikut:

\section{H: Flexible Role Orientation memediasi hubungan antara Lack of Controllability dan Proactive Work Behaviour}

\section{METODE PENELITIAN}

\section{Populasi Dan Sampel}

Populasi yang akan digunakan dalam penelitian ini adalah manajer yang bekerja pada perusahaan manufaktur di Kota Semarang yang terdaftar di Badan Pusat Statistik 2015. Pengumpulan sampel dilakukan dengan metode purposive sampling dengan kriteria manajer perusahaan manufaktur yang ada di Semarang sesuai yang terdaftar di BPS tahun 2015. Perusahaan yang tidak memiliki alamat yang lengkap, tidak merespon panggilan telepon, dan yang menyatakan tidak bersedia menjadi responden dikeluarkan dari sampel. Berdasarkan kriteria ini, jumlah responden yang bersedia untuk berpartisipasi dalam penelitian ini sebanyak 60 orang.

\section{Definisi Dan Pengukuran Variabel Lack of Controllability}

Lack of controllability adalah persepsi karyawan mengenai kurangnya langkahlangkah yang dapat digunakan untuk mengevaluasi kinerja. Variabel tersebut diukur menggunakan kuesioner dengan 3 item pertanyaan dari Burkert et al., 2016 dan menggunakan skala Likert antara 1 hingga 7, dimana (1) Sangat Tidak Setuju, (2) Tidak Setuju, (3) Kurang Setuju, (4) Cukup Setuju, (5) Setuju, (6) Sangat Setuju, (7) Sangat Setuju Sekali. Semakin tinggi skor, semakin tinggi pula lack of controllability.

\section{Flexible Role Orientation}

Flexible role orientation adalah pemahaman tentang struktur, peluang dan ancaman serta resiko yang memungkinkan terjadi flexibilitas peran. Variabel ini diukur mengugunakan kuesioner dengan 7 item pertanyaan dari Burkert et al., (2016) dan menggunakan Skala Likert (Liket Scale) antara 1 hingga 7 dengan alternatif jawaban sebagai berikut: (1) Sangat Tidak Setuju, (2) Tidak Setuju, (3) Kurang Setuju, (4) Cukup Setuju, (5) Setuju, (6) Sangat Setuju, (7) Sangat Setuju Sekali. Skor yang tinggi menunjukan flexible role orientation yang tinggi pula.

\section{Proactive Work Behaviour}

Proactive work behaviour adalah perilaku yang selalu ingin menjalin kerjasama dan komunikasi dengan orang lain dalam rangka membantu unit lain. Variabel ini diukur menggunakan 4 item pertanyaan dari Burkert et al., (2016) menggunakan Skala Likert dengan alternatif jawaban sebagai berikut : (1) Sangat Tidak Setuju, (2) Tidak Setuju, (3) Kurang Setuju, (4) Cukup Setuju, (5) Setuju, (6) Sangat Setuju, (7) Sangat Setuju Sekali. Skor yang tinggi menunjukkan perilaku proaktif yang tinggi pula.

\section{Jenis dan Sumber Data}

Data yang digunakan dalam penelitian ini yaitu data primer karena data yang tersedia dalam penelitian dapat diperoleh secara langsung dari narasumber. Dengan sumber data yang akan diperoleh melalui karyawan yang bekerja pada perusahaan manufaktur yang terberada di kota Semarang. 


\section{Persamaan Regresi}

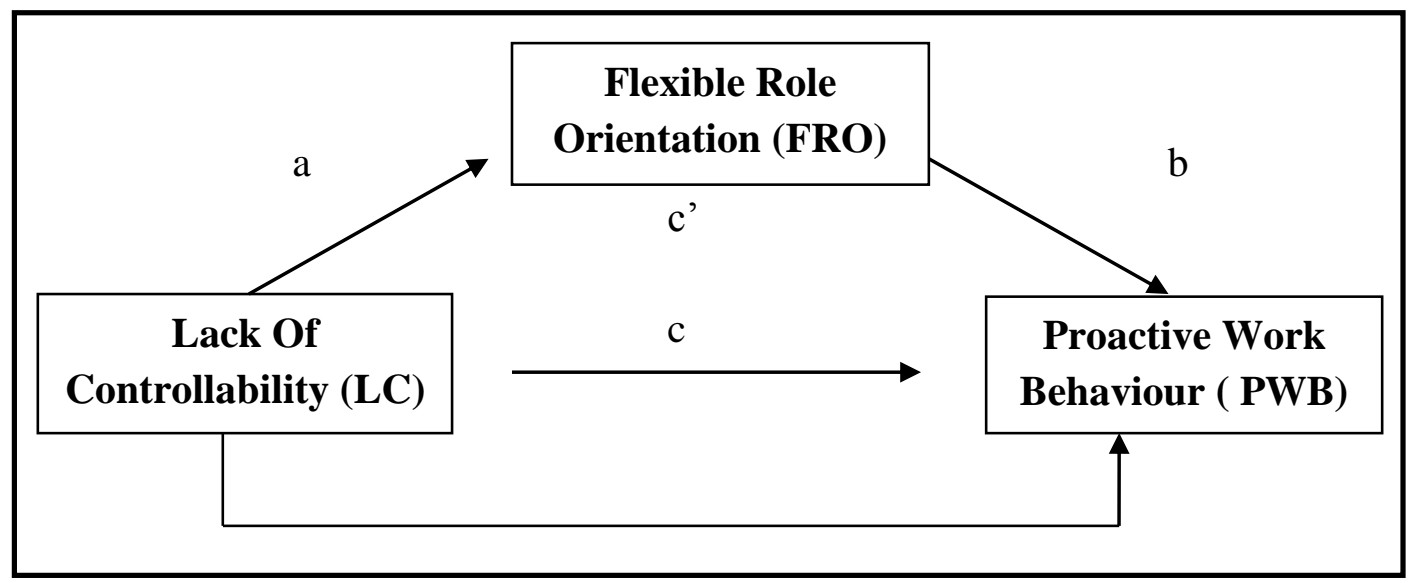

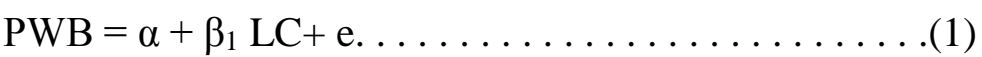

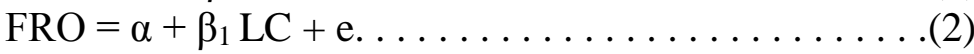

$\mathrm{PWB}=\alpha+\beta_{1} \mathrm{LC}+\beta 2 \mathrm{FRO}+\mathrm{e} \ldots \ldots \ldots \ldots \ldots \ldots$. (3)

\section{Langkah-Langkah Pengujian}

Pengujian Model 1 : menguji pengaruh langsung dari Lack Of Controllability (LC) terhadap Proactive Work Behaviour (PWB).

$$
\mathrm{PWB}=\alpha+\beta_{1} \mathrm{LC}+\mathrm{e}
$$

Menguji model 2 : menguji pengaruh langsung dari Lack Of Controllability (LC) terhadap Flexible Role Orientation (FRO)

$$
\mathrm{FRO}=\alpha+\beta_{1} \mathrm{LC}+\mathrm{e}
$$

Menguji Model 3 : menguji pengaruh langsung dari Lack Of Controllability (LC) dan Flexible Role Orientation (FRO) terhadap Proactive Work Behaviour (PWB)

$$
\mathrm{PWB}=\alpha+\beta_{1} \mathrm{LC}+\beta 2 \mathrm{FRO}+\mathrm{e}
$$

Asumsikan bahwa $\beta_{1}$ pada model 1 sebagai $c$ dan $\beta 2$ pada model 3 sebagai c'. Membandingkan c dan c' serta p-value c dan p-value c' untuk variabel FRO pada persamaan model 1 dan persamaan model 3. Apabila nilai c ke c' meningkat, maka pengaruh LC terhadap PWB akan meningkat, begitu pula berlaku untuk pengujian pada model pengujian lainnya. Selanjutnya dibandingkan pada $\mathrm{p}$-value $\mathrm{c}$ dan $\mathrm{p}$-value $\mathrm{c}^{\prime}$, apabila $\mathrm{p}$-value $\leq 0,10$ maka terjadi hasil yang signifikan antara PWB dengan LC ketika dimediasi dengan FRO.

Menguji model 4 : Menentukan apakah indirect effect tersebut signifikan atau tidak. Pengujian ini menggunakan Sobel test.

\section{HASIL DAN PEMBAHASAN}

\section{Deskripsi Responden}

Pada data yang telah tersedia di Badan Pusat Statistik tahun 2015, diketahui bahwa sejumlah 287 perusahaan manufaktur ada di Kota Semarang. Dari jumlah ini, ada 15 perusahaan yang bersedia menjawab kuesioner. Tabel 1 menyajikan nama-nama perusahaan tersebut dan jumlah kuesioner yang dapat diolah. Pada tahap awal ada 104 kuesioner yang dikirim dan yang kembali sebanyak 79 kuesioner. Dari jumlah ini, 19 kuesioner tidak dapaat 
diolah lebih lanjut karena tidak lengkap dan menyisakan 60 kuesioner yang bisa digunakan untuk menguji hipotesis.

Tabel 1. Deskripsi Kuesioner

\begin{tabular}{|c|c|c|c|c|}
\hline No & Nama Perusahaan & $\begin{array}{c}\text { Kuesioner } \\
\text { yang Dikirim }\end{array}$ & $\begin{array}{c}\text { Kuesioner } \\
\text { yang Kembali }\end{array}$ & $\begin{array}{c}\text { Kuesioner yang } \\
\text { dapat Diolah }\end{array}$ \\
\hline 1 & PT. Majujaya Sarana Grafika & 6 & 4 & 4 \\
\hline 2 & Fumira & 7 & 5 & 4 \\
\hline 3 & PT. Jamu Jago & 9 & 5 & 4 \\
\hline 4 & Virgin Bakery & 7 & 6 & 4 \\
\hline 5 & Jamu Borobudur & 6 & 6 & 4 \\
\hline 6 & Dyriana & 6 & 5 & 4 \\
\hline 7 & PT. Marimas Putra Kencana & 8 & 7 & 4 \\
\hline 8 & Itrasal & 8 & 6 & 4 \\
\hline 9 & Indosigma Surya Cipta & 6 & 5 & 4 \\
\hline 10 & Rapi Garment & 6 & 5 & 4 \\
\hline 11 & Holi Karya Sakti & 9 & 5 & 4 \\
\hline 12 & PT. Raja Besi & 7 & 6 & 4 \\
\hline 13 & Dami Sariwana & 7 & 6 & 4 \\
\hline 14 & Laris Jaya & 6 & 4 & 4 \\
\hline 15 & PT. Semarang Makmur & 6 & 4 & 60 \\
\hline & TOTAL & 104 & 79 & \\
\hline
\end{tabular}

\section{Gambaran Umum Responden}

Data responden yang diperoleh serta dikelompokan berdasarkan jenis kelamin, usia, pendidikan terakhir dan lama bekerja dari manajer yang bekerja pada perusahaan manufaktur di Kota Semarang sebagai berikut :

Tabel 2. Gambaran Umum Responden

\begin{tabular}{|c|c|c|c|}
\hline \multicolumn{2}{|c|}{ Keterangan } & Frek & \% \\
\hline \multirow{2}{*}{ Jenis kelamin } & Laki - laki & 39 & 65,0 \\
\cline { 2 - 4 } & Perempuan & 21 & 35,0 \\
\hline \multirow{2}{*}{ Usia } & $24-30$ Tahun & 22 & 36,7 \\
\cline { 2 - 4 } & $30-40$ Tahun & 38 & 63,3 \\
\hline \multirow{3}{*}{ Pendidikan } & $\mathrm{D} 3$ & 7 & 11,7 \\
\cline { 2 - 4 } & $\mathrm{S} 1$ & 46 & 76,7 \\
\cline { 2 - 4 } & $\mathrm{S} 2$ & 12 & 11,7 \\
\hline \multirow{2}{*}{ Lama Bekerja } & $1-5$ Tahun & 48 & 80,0 \\
\cline { 2 - 4 } & > 5 tahun & & \\
\hline
\end{tabular}

Dari Tabel 2 diketahui bahwa responden berjenis kelamin laki-laki terdapat 39 orang dan perempuan terdapat 21 orang. Hal ini menunjukan responden manajer pada perusahaan manufaktur dikota Semarang lebih banyak yang berjenis kelamin laki-laki. Selanjutnya data responden berdasarkan usia 24-30 tahun berjumlah 22 orang dan usia 30-40 tahun berjumlah 38 orang, artinya responden yang bekerja sebagai manajer pada perusahaan manufaktur di Semarang lebih banyak berusia 30-40 tahun. Kemudian responden yang memiliki masa kerja berkisar 1-5 tahun terdapat 12 orang dan $>5$ tahun terdapat 48 orang, dengan demikian responden karyawan yang bekerja sebagai manajer pada perusahaan manufaktur di Semarang lebih banyak yang bekerja diatas 5 tahun. 
Responden yang berpendidikan D3 berjumlah 7 orang, berpendidikan S1 berjumlah 46 orang dan yang berpendidikan S2 berjumlah 7 orang, sehingga dalam hal ini manajer yang bekerja pada perusahaan manufaktur di Semarang lebih banyak yang berpendidikan S1.

\section{Analisis Deskriptif Responden}

Statistik deskriptif pada penelitian ini bertujuan untuk mengetahui nilai dari jawaban responden terhadap indicator item pertanyaan dalam variabel penelitian. Pertama, dilakukan pembagian kategori skala likert menjadi dua, yaitu rendah dan tinggi. Kedua, menentukan rentang skala dari masing-masing kategori. Kategori rentang skala berdasarkan skala Likert dapat dilihat padaa tabel 3 .

Tabel 3 Kategori Rentang Skala
\begin{tabular}{|c|c|}
\hline Rentang Skala & Kategori \\
\hline $1,00-4,00$ & Rendah \\
\hline $4,01-7,00$ & Tinggi \\
\hline
\end{tabular}

Selanjutnya, Tabel 4 menyajikan perbandingan karakteristik responden. Persepsi responden laki-laki mengenai kurangnya langkah-langkah yang digunakan untuk evaluasi kinerja pengendalian memiliki rata-rata sebesar 5,95 sedangkan perempuan memiliki rata-rata 5,38 persepsi ini termasuk dalam level tinggi. Tingkat signifikansi sebesar 0,02 berarti persepsi kurangnya langkah-langkah yang digunakan untuk evaluasi kinerja pengendalian antara laki-laki dan perempuan terjadi berbedaan signifikan. Persepsi responden laki-laki mengenai pemahaman terhadap struktur, peluang dan ancaman serta resiko yang memungkinkan terjadi untuk flexibilitas peran memiliki rata-rata sebesar 5,67 sedangkan perempuan memiliki rata-rata 5,34 persepsi ini termasuk dalam level tinggi. Tingkat signifikansi sebesar 0,09 berarti persepsi pemahaman terhadap struktur, peluang dan ancaman serta resiko yang memungkinkan terjadi untuk flexibilitas peran antara laki-laki dan perempuan terjadi berbedaan signifikan. Persepsi responden laki-laki mengenai kerjasama dan komunikasi yang dilakukan untuk membantu unit lain memiliki rata - rata sebesar 5,85 sedangkan perempuan memiliki rata-rata 5,43 persepsi ini termasuk dalam level tinggi. Tingkat signifikansi sebesar 0,08 berarti persepsi kerjasama dan komunikasi yang dilakukan untuk membantu unit lain antara laki-laki dan perempuan berbedaan signifikan.

Tabel 4. Compare Mean

\begin{tabular}{|c|c|c|c|c|c|c|c|c|c|c|}
\hline Keterangan & Jumlah & \multicolumn{3}{|c|}{$\mathbf{L C}$} & \multicolumn{3}{|c|}{ FRO } & \multicolumn{3}{|c|}{ PWB } \\
\hline $\mathrm{L}$ & 39 & 5,95 & Tinggi & \multirow{2}{*}{0,02} & 5,67 & Tinggi & \multirow{2}{*}{0,09} & 5,85 & Tinggi & \multirow{2}{*}{0,08} \\
\hline $\mathrm{P}$ & 21 & 5,38 & Tinggi & & 5,34 & Tinggi & & 5,43 & Tinggi & \\
\hline 24-30 Tahun & 22 & 5,50 & Tinggi & \multirow{2}{*}{0,10} & 5,59 & Tinggi & \multirow{2}{*}{0,75} & 5,54 & Tinggi & \multirow{2}{*}{0,32} \\
\hline 30-40 Tahun & 38 & 5,89 & Tinggi & & 5,53 & Tinggi & & 5,78 & Tinggi & \\
\hline D3 & 7 & 5,85 & Tinggi & \multirow{3}{*}{0,43} & 5,43 & Tinggi & \multirow{3}{*}{0,23} & 5,57 & Tinggi & \multirow{3}{*}{0,38} \\
\hline S1 & 46 & 5,67 & Tinggi & & 5,50 & Tinggi & & 5,65 & Tinggi & \\
\hline S2 & 7 & 5,14 & Tinggi & & 6,00 & Tinggi & & 5,14 & Tinggi & \\
\hline 1-5 tahun & 12 & 5,83 & Tinggi & \multirow[b]{2}{*}{0,72} & 5,16 & Tinggi & \multirow[b]{2}{*}{0,04} & 5,75 & Tinggi & \multirow[b]{2}{*}{0,83} \\
\hline $\begin{array}{l}5 \text { tahun } \\
\text { keatas }\end{array}$ & 48 & 5,73 & Tinggi & & 5,65 & Tinggi & & 5,68 & Tinggi & \\
\hline
\end{tabular}

Persepsi responden usia 24-30 tahun mengenai kurangnya langkah-langkah yang digunakan untuk evaluasi kinerja pengendalian memiliki rata - rata sebesar 5,50. Sedangkan 
usia 30-40 tahun memiliki rata - rata sebesar 5,89 dan persepsi ini termasuk dalam level tinggi. Tingkat signifikansi sebesar 0,10 berarti persepsi kurangnya langkah-langkah yang digunakan untuk evaluasi kinerja pengendalian antara usia 24-30 tahun dan usia 30-40 tahun terjadi berbedaan signifikan. Persepsi responden usia 24-30 tahun mengenai pemahaman terhadap struktur, peluang dan ancaman serta resiko yang memungkinkan terjadi untuk flexibilitas peran memiliki rata - rata sebesar 5,59 Sedangkan usia 30-40 tahun memiliki rata - rata sebesar 5,53 dan persepsi ini termasuk dalam level tinggi. Tingkat signifikansi sebesar 0,75 berarti persepsi pemahaman terhadap struktur, peluang dan ancaman serta resiko yang memungkinkan terjadi untuk flexibilitas peran antara usia 24-30 tahun dan usia 30-40 tahun tidak terjadi berbedaan. Persepsi responden usia 24-30 tahun mengenai kerjasama dan komunikasi yang dilakukan untuk membantu unit lain memiliki rata - rata sebesar 5,54. Sedangkan usia 30-40 tahun memiliki rata - rata sebesar 5,78 dan persepsi ini termasuk dalam level tinggi. Tingkat signifikansi sebesar 0,32 berarti persepsi kerjasama dan komunikasi yang dilakukan untuk membantu unit lain antara usia 24-30 tahun dan usia 30-40 tahun tidak terjadi berbedaan.

Persepsi responden dengan pendidikan D3 mengenai kurangnya langkah-langkah yang digunakan untuk evaluasi kinerja pengendalian memiliki rata-rata sebesar 5,85. Pendidikan S1 memiliki rata-rata sebesar 5,67, Pendidikan S2 memiliki rata-rata sebesar 5,14 dan persepsi ini termasuk dalam level tinggi. Tingkat signifikansi sebesar 0,43 berarti persepsi kurangnya langkah-langkah yang digunakan untuk evaluasi kinerja pengendalian antara pendidikan D3, S1 dan S2 tidak terjadi berbedaan. Persepsi responden pendidikan D3 mengenai pemahaman terhadap struktur, peluang dan ancaman serta resiko yang memungkinkan terjadi untuk flexibilitas peran memiliki rata-rata sebesar 5,43. Pendidikan S1 memiliki rata-rata sebesar 5,50. Pendidikan S2 memiliki rata-rata sebesar 6,00 dan persepsi ini termasuk dalam level tinggi. Tingkat signifikansi sebesar 0,23 berarti persepsi pemahaman terhadap struktur, peluang dan ancaman serta resiko yang memungkinkan terjadi untuk flexibilitas peran antara pendidikan D3, S1 dan S2 tidak terjadi berbedaan. Persepsi responden pendidikan D3 mengenai kerjasama dan komunikasi yang dilakukan untuk membantu unit lain memiliki rata-rata sebesar 5,57 Pendidikan S1 memiliki rata-rata sebesar 5,65 Pendidikan S2 memiliki rata-rata sebesar 5,14 persepsi ini termasuk dalam level tinggi. Tingkat signifikansi sebesar 0,38 berarti persepsi kerjasama dan komunikasi yang dilakukan untuk membantu unit lain antara pendidikan D3, S1 dan S2 tidak terjadi berbedaan.

Persepsi responden pekerja 1-5 tahun mengenai kurangnya langkah-langkah yang digunakan untuk evaluasi kinerja pengendalian memiliki rata-rata sebesar 5,83. Sedangkan pekerja 5 tahun keatas memiliki rata-rata sebesar 5,73 persepsi ini termasuk dalam level tinggi. Tingkat signifikansi sebesar 0,72 berarti persepsi kurangnya langkah-langkah yang digunakan untuk evaluasi kinerja pengendalian antara pekerja 1-5 tahun dan 5 tahun keatas tidak terjadi berbedaan. Persepsi responden pekerja 1-5 tahun mengenai pemahaman terhadap struktur, peluang dan ancaman serta resiko yang memungkinkan terjadi untuk flexibilitas peran memiliki rata-rata sebesar 5,16. Sedangkan 5 tahun keatas memiliki rata-rata sebesar 5,65 dan persepsi ini termasuk dalam level tinggi. Tingkat signifikansi sebesar 0,04 berarti persepsi pemahaman terhadap struktur, peluang dan ancaman serta resiko yang memungkinkan terjadi untuk flexibilitas peran antara pekerja 1-5 tahun dan 5 tahun keatas terjadi berbedaan signifikan.

Persepsi responden pekerja 1-5 tahun mengenai kerjasama dan komunikasi yang dilakukan untuk membantu unit lain memiliki rata-rata sebesar 5,75 Sedangkan 5 tahun keatas memiliki rata-rata sebesar 5,68 persepsi ini termasuk dalam level tinggi. Tingkat signifikansi sebesar 0,83 berarti persepsi kerjasama dan komunikasi yang dilakukan untuk membantu unit lain antara pekerja 1-5 tahun dan 5 tahun keatas tidak terjadi perbedaan. 


\section{Hasil Uji Validitas Dan Reliabilitas}

Pengujian validitas digunakan untuk mengukur tiap item pertanyaan dari tiap variabel dilihat valid dan tidaknya dengan membandingkan data dari ketentuan indikator valid ketika indikator tersebut memiliki Cronbach Alpha If item Deleted yang lebih kecil dari nilai Cronbach Alpha instrument. Untuk instrumen atau pertanyaan yang dinyatakan tidak valid maka akan di keluarkan dari pengujian selanjutnya. Hasilnya dapat dilihaat pada tabel 5.

Tabel 5. Validitas Lack Of Controllability

\begin{tabular}{|c|c|c|c|}
\hline Pertanyaan & Cronbach Alpha If item Deleted & Cronbach Alpha & Keterangan \\
\hline LC 1 & 0,652 & 0,719 & Valid \\
\hline LC 2 & 0,561 & 0,719 & Valid \\
\hline LC 3 & 0,663 & 0,719 & Valid \\
\hline
\end{tabular}

Berdasarkan Tabel 5, item pertanyaan untuk mengukur Lack Of Controllability (LC) valid yang ditunjukan dari Cronbach Alpha If item Deleted yang lebih kecil Cronbach Alpha instrumen.

Tabel 6. Pengujian Validitas Flexible Role Orientation

\begin{tabular}{|c|c|c|c|}
\hline Pertanyaan & Cronbach Alpha If item Deleted & Cronbach Alpha & Keterangan \\
\hline FRO 1 & 0,745 & 0,761 & Valid \\
\hline FRO 2 & 0,758 & 0,761 & Valid \\
\hline FRO 3 & 0,732 & 0,761 & Valid \\
\hline FRO 4 & 0,740 & 0,761 & Valid \\
\hline FRO 5 & 0,713 & 0,761 & Valid \\
\hline FRO 6 & 0,731 & 0,761 & Valid \\
\hline FRO 7 & 0,698 & 0,761 & Valid \\
\hline
\end{tabular}

Dari Tabel 6 dapat dilihat variabel Flexible Role Orientation (FRO) dinyatakan Valid dengan di tunjukan dari Cronbach Alpha If item Deleted lebih kecil Cronbach Alpha instrumen.

Tabel 7. Pengujian Validitas Proactive Work Behaviour

\begin{tabular}{|c|c|c|c|}
\hline Pertanyaan & Cronbach Alpha If item Deleted & Cronbach Alpha & Keterangan \\
\hline PWB 1 & 0,746 & 0,783 & Valid \\
\hline PWB 2 & 0,656 & 0,783 & Valid \\
\hline PWB 3 & 0,777 & 0,783 & Valid \\
\hline PWB 4 & 0,728 & 0,783 & Valid \\
\hline
\end{tabular}

Dari Tabel 7 dapat dilihat variabel Proactive Work Behaviour $(P W B)$ dinyatakan Valid dengan di tunjukan dari Cronbach Alpha If item Deleted lebih kecil Cronbach Alpha instrumen.

Tabel 8. Pengujian Reliabilitas

\begin{tabular}{|c|c|c|}
\hline Variabel & Cronbach Alpha & Keterangan \\
\hline LC & 0,719 & Reliabel \\
\hline FRO & 0,761 & Reliabel \\
\hline PWB & 0,783 & Reliabel \\
\hline
\end{tabular}


Dari Tabel 8 dapat diketahui bahwa dari tiap - tiap variabel memiliki nilai Cronbach Alpha yang reliabel, termasuk dalam golongan reliabilitas tinggi pada setiap variabel yang ada.

\section{Uji Normalitas}

Uji Normalitas ini dimaksudkan untuk mendeteksi data - data yang digunakan dalam menguji suatu hipotesis dengan data yang normal dan tidak terdapat outlier. Uji normalitas untuk setiap hipotesis ini akan menggunakan pengujian Kolmogorov-Smirnov sebagai berikut :

Tabel 9. Hasil Uji Normalitas

\begin{tabular}{|c|c|c|c|}
\hline Model & Persamaan & Sig & Ket \\
\hline Model 1 & PWB $=\alpha+\beta_{1}$ LC $+\mathrm{e}$ & 0,102 & Normal \\
\hline Model 2 & FRO $=\alpha+\beta_{1}$ LC + e & 0,272 & Normal \\
\hline Model 3 & PWB $=\alpha+\beta_{1}$ LC $+\beta 2$ FRO + e & 0,169 & Normal \\
\hline
\end{tabular}

Hasil uji normalitas pada tabel 9 menunjukkan bahwa data yang tersaji berdistribusi normal, karena nilai Kolmogorov-Smirnov dan Asymp.Sig (2tailed) memiliki nilai lebih besar 0,05 pada tiap persamaan mulai dari model 1 - model 3 .

\section{Uji Heteroskedastisitas}

Pengujian heteroskedastisitas dimaksudkan untuk melihat keragaman pada variabel independen yang bervariasi pada data yang ada di tiap sampel tetapi memiliki keragaman residual atau eror yang tidak bersifat konstan. Maka pengujian heterokedastisitas dilakukan dengan uji Glejser.

Tabel 10. Uji Heteroskedastisitas

\begin{tabular}{|c|c|c|c|c|}
\hline Model & Persamaan & Variabel Independen & Sig & Ket \\
\hline Model 1 & PWB $=\alpha+\beta_{1}$ LC $+\mathrm{e}$ & LC & 0,970 & Lolos \\
\hline Model 2 & FRO $=\alpha+\beta_{1}$ LC $+\mathrm{e}$ & LC & 0,053 & Lolos \\
\hline \multirow{2}{*}{ Model 3 } & \multirow{2}{*}{ PWB $=\alpha+\beta_{1}$ LC $+\beta 2$ FRO + e } & FRO & 0,790 & Lolos \\
\cline { 3 - 5 } & & LC & 0,650 & Lolos \\
\hline
\end{tabular}

Dari tabel 10 dapat dilihat semua variabel di tiap persamaan dalam hipotesis model 1, 2 dan 3 tidak terjadi heteroskedastisitas dengan nilai Sig lebih besar 0,05 dan 92 variabel independennya tidak memiliki pengaruh pada absolute standardized residual.

\section{Uji Multikolinearitas}

Tabel 11. Uji Multikolinearitas

\begin{tabular}{|c|c|c|c|c|c|}
\hline Model & Persamaan & Variabel Independen & Tollerance & VIF & Ket \\
\hline \multirow{2}{*}{ Model 3 } & PWB $=\alpha+\beta_{1} \mathrm{LC}+\beta 2$ & FRO & 0,377 & 2,652 & Lolos \\
\cline { 3 - 6 } & FRO $+\mathrm{e}$ & LC & 0,377 & 2,652 & Lolos \\
\hline
\end{tabular}

Pada pengujian multikolinearitas dapat dideteksi dengan menghitung koefisien korelasi ganda serta membandingkannya dengan koefisiensi korelasi antar variabel bebas. Pada pengujian ini dapat dilakukan dengan SPSS dengan uji regresi yang berpedoman pada nilai VIF (Variance inflation factor) dan koefisien korelasi antar variabel bebas. 
Berdasarkan tabel 11 diatas diketahui bahwa model 3 tidak mengalami multikolinearitas dikarenakan nilai Tolerance tidak lebih dari 1, dan nilai Variance Inflation Factor (VIF) tidak lebih dari 10.

\section{Uji Hipotesis}

Pada pengujian hipotesis akan dilakukan dengan beberapa persamaan mediasi, dan uji selanjutnya menggunkana Sobel Test. Hasilnya dapat dilihat pada tabel 12 .

Tabel 12. Hasil pengujian Hipotesis

\begin{tabular}{|c|c|c|c|c|c|c|c|c|c|}
\hline \multirow{3}{*}{ Variabel } & \multicolumn{3}{|c|}{ Model 1} & \multicolumn{3}{|c|}{ Model 2} & \multicolumn{3}{|c|}{ Model 3} \\
\hline & \multicolumn{3}{|c|}{$\mathbf{P W B}=\alpha+\beta_{1} \mathrm{LC}+\mathrm{e}$} & \multicolumn{3}{|c|}{$\mathrm{FRO}=\alpha+\beta_{1} \mathrm{LC}+\mathrm{e}$} & \multicolumn{3}{|c|}{$\begin{array}{c}\mathrm{PWB}=\alpha+\beta_{1} \mathrm{LC}+\beta 2 \mathrm{FRO}+ \\
\mathrm{e}\end{array}$} \\
\hline & B & $\mathbf{T}$ & Sig & B & $\mathbf{T}$ & Sig & B & $\mathbf{T}$ & Sig \\
\hline (Constant) & 0,968 & 2,562 & 0,013 & 2,010 & 4,877 & 0,000 & 0,373 & 0,871 & 0,378 \\
\hline $\mathrm{LC}$ & 0,841 & 13,526 & 0,000 & 0,663 & 9,788 & 0,000 & 0,645 & 6,668 & 0,000 \\
\hline FRO & & & & & & & 0,296 & 2,574 & 0.013 \\
\hline
\end{tabular}

$\mathrm{c} ; \beta=0,841^{*} \mathrm{p}$-value $=0,000$

$c^{\prime}: \beta=0,645^{*}$ p-value $=0,000$

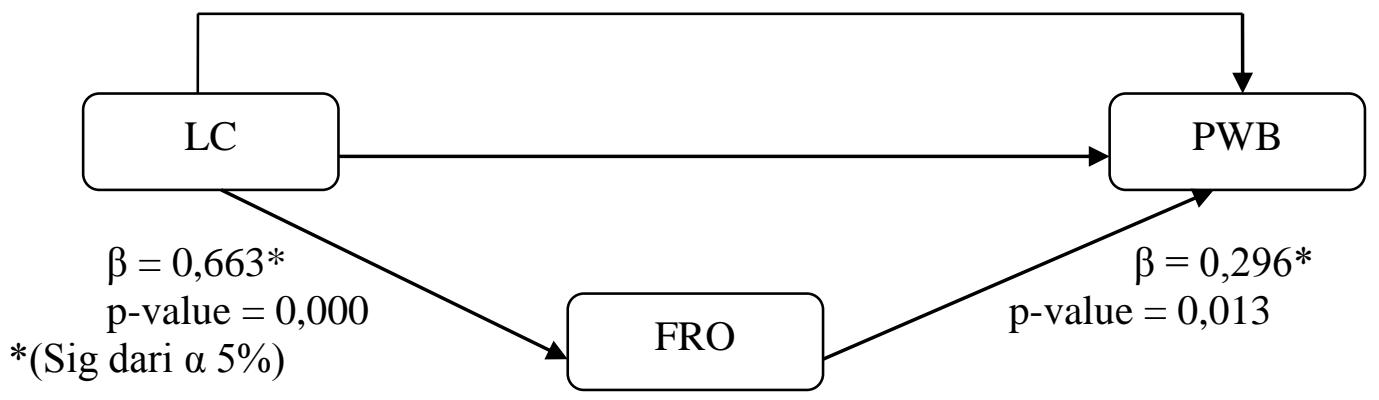

Berdasarkan hasil pengujian hipotesis dengan menggunakan pendekatan Causal Step maka pengaruh Lack of Controllability terhadap Proactive Work Behaviour setelah memasukan variabel mediasi Flexible Role Orientation menurun dari 0,841 menjadi 0,645 dan pengaruh tersebut menjadi signifikan karena ( $p$-value $\mathrm{c}=0,000$ menjadi $p$-value $\mathrm{c}^{\prime}=$ 0,000). Artinya Flexible Role Orientation adalah Partial mediation variabel.

Total Effect $=$ Direct Effect + Indirect Effect

$$
0,841=0,645+(0,663 * 0,296)
$$

Kemudian pengujian indirect effect diuji dengan menggunakan sobel test dan hasilnya ditampilkan dalam tabel 13. Hasil yang ditampilkan merupakan pengujian mediasi dengan melihat hasil dari sobel test, aroian test, goodman test. Hasil pengujian memalui sobel test bahwa indirect effect terlihat bahwa hasilnya significan dengan nilai pada kolom $p$-value yaitu dari pengujian sobel test $(0,01)$, aroian test $(0,01)$, goodman test $(0,01)$ dimana angka yang ditunjukan lebih kecil dari 5\%. Sehingga, hipotesis tersebut menyatakan Lack Of Controllability berpengaruh terhadap Proactive Work Behaviour melalui Flexible Role Orientation dinyatakan diterima. 
Tabel 13. Sobel test

\begin{tabular}{|c|c|c|c|c|c|}
\hline & Input: & & Test statistic: & Std. Error: & p-value: \\
\hline$a$ & 0.663 & Sobel test: & 2.48865469 & 0.07885706 & 0.01282274 \\
\hline$b$ & 0.296 & Aroian test: & 2.47650743 & 0.07924386 & 0.01326749 \\
\hline & 0.068 & Goodman test: & 2.50098246 & 0.07846836 & 0.01238493 \\
\hline & 0.115 & Reset all & \multicolumn{3}{|c|}{ Calculate } \\
\hline
\end{tabular}

Alternatively, you can insert $t_{a}$ and $t_{b}$ into the cells below, where $t_{a}$ and $t_{b}$ are the $t$-test statistics for the difference between the $a$ and $b$ coefficients and zero. Results should be identical to the first test, except for error due to rounding.

\section{Hipotesis}

\begin{tabular}{|c|c|c|c|}
\hline Input: & & Test statistic: & p-value: \\
\hline$t_{a} 9.788$ & Sobel test: & 2.48936183 & 0.01279727 \\
\hline \multirow[t]{3}{*}{$t_{b} 2.574$} & Aroian test: & 2.47729861 & 0.01323811 \\
\hline & Goodman test: & 2.50160301 & 0.01236325 \\
\hline & Reset all & \multicolumn{2}{|c|}{ Calculate } \\
\hline
\end{tabular}

\section{Pembahasan}

Hasil dari penelitian ini menunjukan bahwa (Lack Of Controllability) semakin tinggi kurangnya langkah - langkah yang digunakan untuk evaluasi kinerja pengendalian yang mengarah pada hal negatif, maka akan memberikan (Flexible Role Orientation) pemahaman terhadap struktur, peluang dan ancaman serta resiko yang memungkinkan terjadi semakin baik, sehingga semakin tinggi flexibilitas peran yang ada semakin tinggi pula (Proactive Work Behaviour) kerjasama dan komunikasi yang mudah terjalin untuk membantu unit kerja lain. Hal tersebut sesuai dengan teori Dua faktor oleh Frederick Herzberg (1923-2000) yaitu faktor intrinsik dan faktor ekstrinsik, dimana faktor intrinsik adanya pemahanan terhadap struktur, peluang dan ancaman serta resiko yang memungkinkan flexibilitas peran yang semakin tinggi sehingga perilaku proaktif seseorang meningkat dan faktor ekstrinsik yaitu adanya evaluasi kinerja pengendalian menurun yang menyebabkan flexibilitas peran meningkat, dengan demikian akan memberikan kemudahan dalam berkomunikasi serta menjalin kerjasama antar departemen yang ada.

Hal ini juga sesuai dengan teori peran (Shaw and Constanzo,1970). Peran mencerminkan posisi seseorang dalam sistem sosial dengan hak dan kewajiban, kekuasaan serta tanggung jawab yang menyertainya. Untuk dapat berinteraksi satu sama lain, orangorang memerlukan cara tertentu guna mengantisipasi perilaku orang lain. Peran melakukan fungsinya dalam sistem sosial, seseorang memiliki peran baik dalam pekerjaan maupun di luar itu, masing - masing peran memiliki konsekuensi perilaku yang berbeda - beda dalam lingkungan pekerjaan itu sendiri. Seorang karyawan mungkin memiliki lebih dari satu peran, seorang karyawan bisa berperan sebagai bawahan, penyedia, anggota serikat pekerja, dan wakil dalam panitia keselamatan kerja.

Pada dasarnya Lack Of Controllability yang menurun akan meningkatkan flexibilitas peran sehingga perilaku proaktif pun meningkat. Dalam hal ini, sejalan dengan seseorang yang memiliki posisi tertentu sehingga orang tersebut akan memiliki peran sesuai dengan posisinya, perilaku yang dilakukanpun sesuai dengan posisi yang sedang dijabatnya. Demikian pula, dengan manajer yang mungkin mengalami situasi dimana faktor yang kurang terkendali dari Lack of Controllability itu sendiri sehingga orientasi peran fleksibel meningkat serta lebih mudah dalam meningkatkan efek dasar pada perilaku kerja proaktif. Lack of controlability memberikan pengaruh pada Flexible Role Orientation dimana pemahaman terhadap struktur, peluang dan ancaman serta resiko yang memungkinkan terjadi 
untuk flexibilitas peran akan berdampak pada Proactive work Behaviour sehingga akan mempermudah manajer untuk bekerjasama dan berkomunikasi dengan unit lain (Burkert et al., 2016). Hasil penelitian ini menerima Hipotesis yang ada yaitu Flexible Role Orientation memediasi hubungan antara Lack of Controllability terhadap Proactive Work Behaviour.

\section{KESIMPULAN DAN SARAN}

Kurangnya kemampuan dalam mengendalikan situasi pada saat bekerja dapat menurunkan motivasi manajerial dan memicu stres peran yang tinggi (Giraud et al., 2008). Lebih jauh, kurangnya kemampuan dalam mengendalikan situasi menghalangi manajer untuk dapat berkomunikasi dan bekerjasama dengan manajer lain. Hasil penelitian sebelumnya menunjukkan bahwa kurangnya pengendalian mendorong munculnya perilaku proaktif dalam diri karyawan. Namun hubungan ini hanya mungkin terjadi jika ada fleksibilitas peran. Kurangnya kemampuan dalam mengendalikan situasi meningkatkan konflik peran yang pada akhirnya mendorong orientasi peran yang lebih fleksibel dan diprediksi menghasilkan tingkat perilaku proaktif yang lebih tinggi.

Penelitian ini bertujuan untuk menguji ulang penelitian Burkert et al., (2016) dengan menambah variabel mediasi orientasi fleksibilitas peran dan sampel menggunakan manajer yang bekerja pada perusahaan manufaktur di kota Semarang. Hasil pengujian menunjukkan bahwa flexible role orientation dapat memediasi hubungan antara lack Of controllability dan proactive work behaviour.

\section{Saran}

Saran dari penelitian ini untuk dilakukan pada penelitian selanjutnya yaitu mengenai penelitian bisa dilakukan di perusahaan bidang industri yang lain. Ditinjau dari nilai deskriptif masing - masing variabel :

1. Bagi manajer perusahan manufaktur di Semarang.

Penetapan target pada kondisi pengendalian tertentu akan mendorong flexibilitas peran dan pada akhirnya meningkatkan kinerja proaktif. Manajer melalui pengalaman dengan berbagai kondisi pengendalian, hendaknya melakukan pengamatan terhadap efek kinerja. Sehingga mampu menemukan batas pengendalian yang memungkinkan flexibilitas peran terjadi.

2. Bagi riset selanjutnya.

Penelitian ini mendukung aplikasi teori peran dalam menghasilkan perilaku yang sama dengan manajer saat terjadi Lack Of Controllability untuk meningkatkan external validity dengan menguji sampel yang sama.

\section{DAFTAR PUSTAKA}

Bindl, U.K. and S.K, Parker., 2011. Proactive work behavior: forward-thinking and changeoriented action in organizations. In: S. Zedeck, ed. APA Handbook of Industrial and Organizational Psychology. Washington, DC: American Psychological Association, 2 (1): 567-598.

Burkert, M., F.M, Fischer., F, Hoos., K, Schuhmacher., 2016. The relationship between lack of controllability and proactive work behaviour: an empirical analysis of competing theoretical explanations The relationship between lack of controllability and proactive work behaviour : an empirical analysis of competing , 4788. 
Chapman, A., 2010. Frederick Herzber's Motivation and Hygine Factors. Diambil dari http://www.businessballs.com/herzberg.htm. Pada 22 September 2017

Choudhury, N., 1986., Responsibility accounting and controllability. Accounting and Business Research, 16 (3): 189-198.

Crant, J.M., 2000. Proactive behavior in organizations. Journal of Management, 26 (3): 435462.

Dent, J.F. 1987. Tensions in the design of formal control systems: a field study in a computer company. In: W.J. Bruns and R.S. Kaplan, eds. Accounting and Management: Field Study Perspectives. Boston, MA: Harvard Business School Press: 119-145.

Frow, N., D, Marginson., and S, Ogden. 2005. Encouraging strategic behaviour while maintaining management control: multi-functional project teams, budgets, and the negotiation of shared accountabilities in contemporary enterprises. Management Accounting Research, 16 (3), 269-292.

Giraud, F., P, Langevin., and C, Mendoza. 2008. Justice as a rationale for the controllability principle: a study of managers' opinions. Management Accounting Research, 19 (1): $32-44$.

Grant, A.M. and D.A, Hofmann. 2011. Role expansion as a persuasion process: the interpersonal influence dynamics of role redefinition. Organizational Psychology Review, 1 (1): 9-31.

Hartono, J. 2010. Metodologi Peneltian : Salah Kaprah dan Pengalaman - Pengalaman. BPFE - Yogyakarta.

Kahn, R.L., D.M, Wolfe., R.P, Quinn., J.D, Snoeck., and R.A, Rosenthal., 1964. Organizational Stress: Studies in Role Conflict and Ambiguity. New York: Wiley.

Manzoni, J.-F., 2002. Management control: toward a new paradigm? In: M.J. Epstein and J.F. Manzoni, eds. Performance Measurement and Management Control: A Compendium of Research. Amsterdam: Elsevier, 15-46.

Merchant, K.A. 1987. How and why firms disregard the controllability principle. In: W.J. Bruns and R.S. Kaplan, eds. Accounting and Management: Field Study Perspectives. Boston, MA: Harvard Business School Press, 316-338.

Murniati, M. P., Purnamasari, S. V., Ratnaningsih, S. D. A., Advensia, A., Sihombing, R. P., \& Warastuti, Y. (2013). Alat - alat Pengujian Hipotesis. Semarang: Unika Soegijapranata.

Parker, S.K. 2007. That is my job: how employees' role orientation affects their job performance. Human Relations, 60 (3), 403-434.

Parker, S.K., T.D, Wall., and P.R, Jackson., 1997. That's not my job: developing flexible employee work orientations. Academy of Management Journal, 40 (4), 899-929.

Parker, S.K., H.M, Williams., and N, Turne., 2006. Modeling the antecedents of proactive behavior at work. Journal of Applied Psychology, 91 (3), 636-652.

Perrone, V., A, Zaheer., and B, McEvily. 2003. Free to be trusted Organizational constraints on trust in boundary spanners. Organization Science, 14 (4), 422-439.

Simons, R., 2010. Accountability and control as catalysts for strategic exploration and exploitation: field study results. Harvard Business School Working Paper Series No. 10-051, Harvard Business School. 
Strauss, K., M.A, Griffin., and S.K, Parker. 2012. Future work selves: how salient hoped-for identities motivate proactive career behaviors. Journal of Applied Psychology.

Unsworth, K.L. and S.K, Parker. 2003. Proactivity and innovation: promoting a new workforce for the new workplace. In: D. Holman, T.D.Wall, C.W. Clegg, P. Sparrow, and A. Howard, eds. The NewWorkplace: A Guide to the Human Impact of Modern Work Practices. Chichester: Wiley, 175-196.

$\mathrm{Wu}$, C.H. and S.K, Parker. 2011. Proactivity in the work place: looking back and looking forward. In: K.S. Cameron and G.M. Spreitzer, eds. Oxford Handbook of Positive Organizational Scholarship. Oxford: Oxford University. 